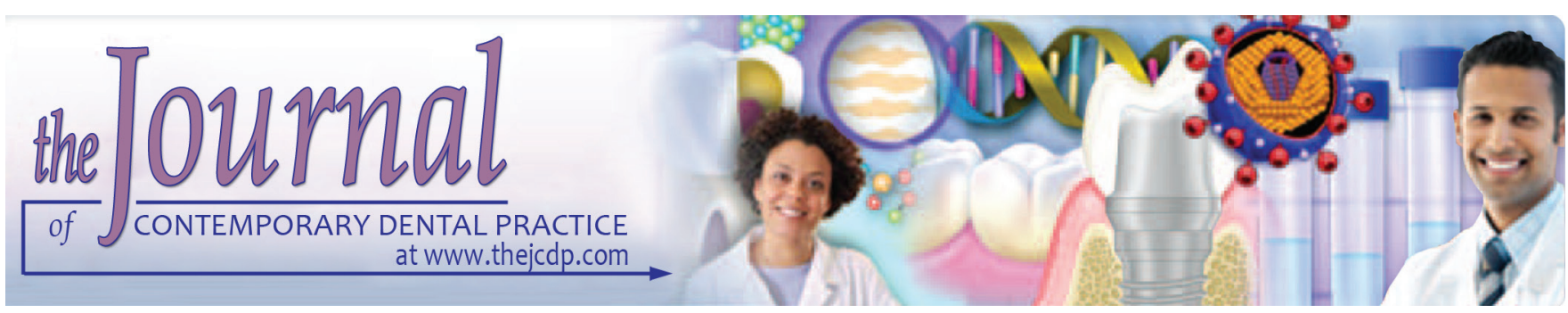

\title{
Effect of Over-the-counter Whitening Products associated or Not with $10 \%$ Carbamide Peroxide on Color Change and Microhardness: in vitro Study
}

${ }^{1}$ Ana LB Jurema, ${ }^{2}$ Evaniele S Claudino, ${ }^{3}$ Carlos RG Torres, ${ }^{4}$ Eduardo Bresciani, ${ }^{5}$ Taciana MF Caneppele

\begin{abstract}
Aim: The purpose of this in vitro study was to evaluate the color and microhardness of teeth subjected to different overthe-counter (OTC) whitening products in association or not with $10 \%$ carbamide peroxide $(10 \% \mathrm{CP})$.
\end{abstract}

Materials and methods: Enamel-dentin specimens $(n=210)$ were obtained from bovine incisors and stained. Half of the specimens were then subjected to daily cycles of staining (5 minutes), 10\% CP bleaching (8 hours) in association with OTC products, and artificial saliva storage until complete 24 hours, for 2 weeks; the other half was subjected to daily cycles of staining, OTC treatment, and storage in artificial saliva for 12 weeks. The specimens were divided into 14 groups according to the OTC: CP-Water and Water (deionized water); CP-Listerine and Listerine (whitening mouth rinse); CP-Brushing and Brushing (mechanical brushing); CP-Colgate and Colgate (conventional toothpaste), CP-ColgateW and ColgateW, CP-OralBW and OralBW, and CP-CloseUpW and CloseUpW (whitening toothpaste). After staining and whitening, color and microhardness were measured. Data were submitted to analysis of variance (ANOVA) and the Tukey's test for multiple comparisons for color analysis and the paired t-test for microhardness analysis.

Results: The CP and CloseUpW groups had the largest color change $\left(\Delta \mathrm{E}_{00}\right)$. The teeth treated with Colgate increased significantly in microhardness after whitening

Conclusion: The association of $10 \%$ CP with OTC whitening agents did not increase the whitening effect or microhardness. The OTC agents containing hydrogen peroxide and abrasives had a similar effect to one another but were not as effective as the CP groups and the subgroup brushed only with blue covarine toothpaste.

\footnotetext{
${ }^{1-5}$ Department of Restorative Dentistry, São Paulo State University, Institute of Science and Technology, São Paulo Brazil

Corresponding Author: Taciana MF Caneppele, Department of Restorative Dentistry, São Paulo State University, Institute of Science and Technology, São Paulo, Brazil, Phone: +551239479304, e-mail: taciana.caneppele@unesp.br
}

Clinical significance: The current study provides information about the mechanism of OTC whitening products. None of the whitening agents evaluated damaged the enamel when used according to the manufacturers' instructions. The use of toothpaste containing hydrogen peroxide or abrasives cannot provide a whitening effect similar to at-home bleaching, and this does not improve with the association with 10\% CP. However, toothpaste containing blue covarine has a satisfactory whitening effect immediately after brushing.

Keywords: Laboratory research, Mouthwashes, Tooth bleaching, Toothpaste.

How to cite this article: Jurema ALB, Claudino ES, Torres CRG, Bresciani E, Caneppele TMF. Effect of Over-the-counter Whitening Products associated or Not with 10\% Carbamide Peroxide on Color Change and Microhardness: in vitro Study. J Contemp Dent Pract 2018;19(4):359-366.

Source of support: This work was supported by São Paulo Research Foundation (FAPESP) (grant \#2015/22943-0).

Conflict of interest: None

\section{INTRODUCTION}

As whiter tooth color has a positive effect on self-esteem and quality of life, more patients seek oral rehabilitation treatment. Therefore, professionals must be able to treat tooth staining, which most often is the main complaint of their patients. ${ }^{1,2}$ Extrinsic tooth staining can be associated with the intake of colored foods. It can also be promoted by biofilm accumulation and dental calculus, smoking, medications, and the use of substances, such as chlorhexidine or those containing metal salts. ${ }^{3,4}$ Such staining can be removed by professional prophylaxis or subgingival scaling. However, as tooth staining may still be noticeable, tooth-whitening techniques are indicated. ${ }^{3-8}$

Chemical reactions of peroxide-based whitening agents on the tooth surface result in the penetration of molecules into the tooth structure. This breaks the 
pigment molecules into simpler chains in a redox reaction, decreasing the optical absorption of light. ${ }^{9}$ Hydrogen peroxide is the most commonly used agent for dental whitening and is used in different concentrations according to the technique (in-office or at-home). For the at-home method, hydrogen peroxide in lower concentrations (3-10\%) and also CP (10-22\%) are commonly used. ${ }^{4,10,11}$ In addition to traditional whitening treatments, OTC whitening products, such as dentifrices and mouth rinses have been developed and are available to consumers without a professional prescription or monitoring. Mouth rinses may have only low concentrations of hydrogen peroxide (1-2\%) in their formulation. Toothpastes have different mechanisms for promoting tooth whitening, including abrasive particles (such as hydrated silica), chemical agents (such as hydrogen peroxide), and optical whiteners (such as blue covarine). The whitening efficacy of OTC products is controversial, and some authors have observed that their whitening effect is lower than that obtained by conventional whitening with $10 \%$ CP. They can lighten darkened enamel, but the whitening effect is greater with $10 \% \mathrm{CP} .{ }^{12}$ The presence of blue covarine or hydrogen peroxide in toothpaste may be less effective than in-office $35 \%$ hydrogen peroxide or at-home $10 \%$ $\mathrm{CP}$ bleaching agents. ${ }^{13}$ Some mouthwashes increase the whiteness of teeth over time, but, with their lower concentration of hydrogen peroxide, they are less effective than at-home bleaching. ${ }^{14}$ However, one study showed that mouthwashes containing 1.5 and $2 \%$ of hydrogen peroxide produced color alteration similar to that of 14 days of $10 \%$ CP bleaching. ${ }^{15}$ Manufacturers, advertising, and media reports have suggested that OTC products, even toothpaste and mouthwashes, can be as effective as professional whitening techniques.

Microhardness is related to the surface mineral content of the enamel. The demineralization and remineralization process of the enamel occurs due to the contact of the surface with substances with $\mathrm{pH}$ values different from that of saliva; more acidic substances can decrease the enamel mineral content, and materials containing components, such as sodium fluoride can contribute to enamel remineralization. Consequently, changes in hardness can occur. ${ }^{16}$ Abrasive dentifrices associated with a $\mathrm{pH}$ change in the environment can also modify the enamel hardness. ${ }^{17}$ The use of bleaching gels can alter the enamel surface hardness by means of different $\mathrm{pH}$ values and surface oxidation. ${ }^{18,19}$ For these reasons, an evaluation of the influence of dentifrices and bleaching rinses on enamel hardness is essential, since the presence of hydrogen peroxide and abrasives can alter the tooth surface ${ }^{20}$ and because of the possible addition of $10 \% \mathrm{CP}$ at-home bleaching. The number of studies assessing whitening mouth rinses and toothpastes is increasing. However, to obtain more information about the mechanisms of OTC whitening products, more studies comparing different mouth rinses and toothpastes with at-home whitening treatments are required.

This study aimed to evaluate the color and microhardness of teeth submitted to different OTC whitening products (mouth rinses and toothpaste), with or without 10\% CP whitening treatment.

\section{MATERIALS AND METHODS}

\section{Specimen Preparation and Distribution}

Seventy extracted, intact bovine incisors were used. Cylindrical enamel-dentin specimens ( $3 \mathrm{~mm}$ in diameter and $2.1 \mathrm{~mm}$ in height:1.1 $\mathrm{mm}$ of enamel and $1 \mathrm{~mm}$ of dentin) were prepared using a trephine mill (FN Moraes, São José dos Campos, São Paulo, Brazil). Three specimens were obtained from each tooth.

The specimens were mounted in silicone molds of $6 \mathrm{~mm}$ in diameter and $3.1 \mathrm{~mm}$ in depth. At the bottom of each mold, there was an additional cavity $(3 \mathrm{~mm}$ in diameter and $0.1 \mathrm{~mm}$ in depth). The specimens were positioned inside the internal cavities with their enamel surfaces directed toward the bottom of the molds. Each mold was filled with autopolymerizing acrylic resin (Jet, Clássico LTDA, Campo Limpo Paulista, São Paulo, Brazil) and placed in an acrylic resin polymerizing container, immersed in water, and submitted to 30 psi pressure to avoid air bubble formation until complete polymerization. The specimens were positioned in a metal device, and the enamel surfaces were polished using sequential aluminum oxide abrasive papers (1200, 2400, and 4000 grit FEPA-P, Struers, Ballerup, Denmark) in a polishing device (DP-10, Panambra, São Paulo, Brazil).

The specimens were stained for 14 days under constant agitation in a staining broth (136.5 gm of finely ground instant coffee; 136.5 gm of finely ground instant tea; $30 \mathrm{~mL}$ Food, Drug, and Cosmetic (FD\&C) Red 40, $30 \mathrm{~mL}$ FD\&C Yellow 5, and 3.8 L red wine) adapted from Wozniak et al. ${ }^{21,22}$

After staining, the specimens were repolished with aluminum oxide abrasive papers (4000 grit FEPA-P) in a polishing device to remove the excess adsorbed stain and were randomly divided into 14 groups $(n=15)$. Seven groups were submitted to OTC whitening treatment combined with 10\% CP at-home bleaching (Opalescence 10\%, Ultradent Products Inc., South Jordan, Utah, USA). The other seven groups were submitted only to OTC whitening treatment. Flow Chart 1 illustrates the design of this study.

\section{Brushing and Rinsing Cycles}

The treatment protocol of groups treated with OTC whitening treatment associated with $10 \% \mathrm{CP}$ was as follows: 
Flow Chart 1: Study design

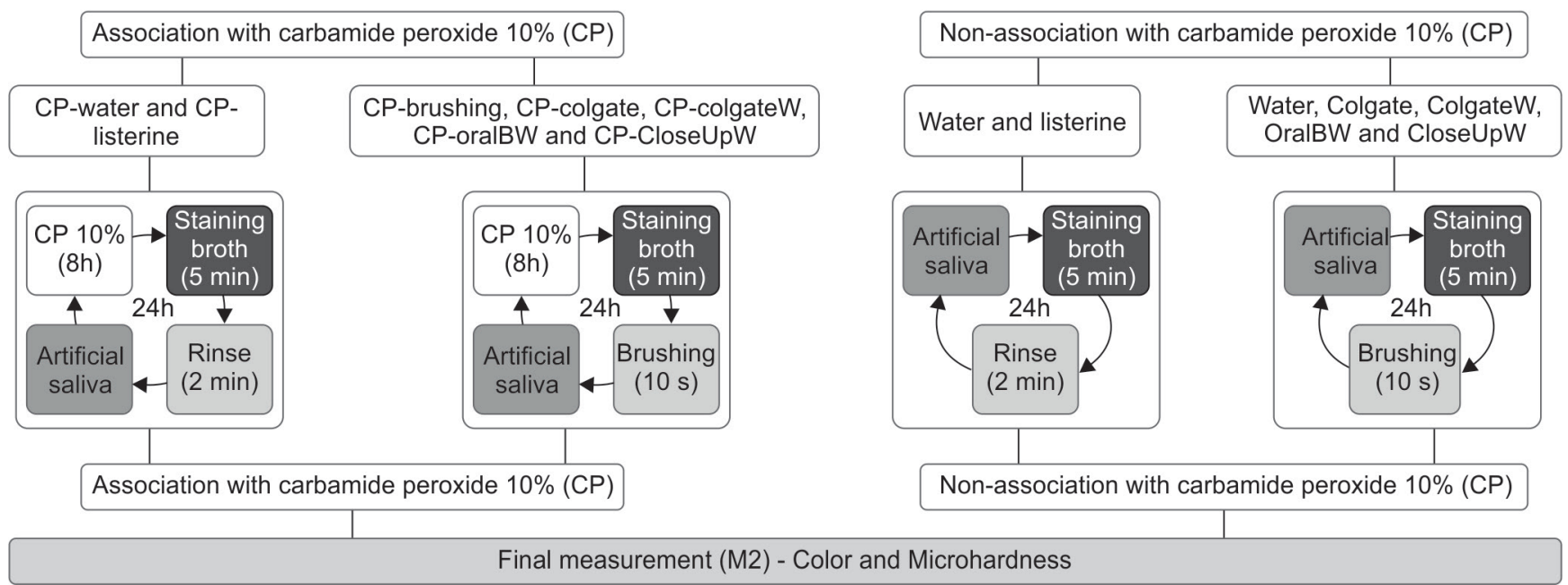

Each specimen was treated with 10\% CP gel 8 hours / day, immersed in the staining broth for 5 minutes, rinsed for 2 minutes (CP-Water and CP-Listerine), or brushed for 10 seconds (CP-Brushing, CP-Colgate, CP-ColgateW, CP-OralBW, and CP-CloseUpW), and stored in artificial saliva for the remaining time until completion of the 24-hour cycle for 2 weeks (Flow Chart 1).

For the groups subjected only to OTC whitening treatment, the following protocol was used: Each specimen was immersed in the staining broth for 5 minutes, rinsed for 2 minutes (for Water and Listerine), or brushed for 10 seconds (Brushing, Colgate, ColgateW, OralBW, and Close UpW), and stored in artificial saliva for the remaining time until completion of the 24-hour cycle for 12 weeks. The specimens in the brushing groups were brushed only with a toothbrush, without a dentifrice or other product.

Table 1 shows the products used in this study, including details of the manufacturers and of their components.

Artificial saliva was prepared according to Göhring et $\mathrm{al}^{23}: 12 \mathrm{gm}$ of $\mathrm{KCl} ; 8.5 \mathrm{gm}$ of $\mathrm{NaCl} ; 0.5 \mathrm{gm}$ of $\mathrm{MgCl}_{2} \bullet 6 \mathrm{H}_{2} \mathrm{O} ; 3.5 \mathrm{gm}$ of $\mathrm{H}_{2} \mathrm{KPO}_{4} ; 0.5 \mathrm{gm}$ of $\mathrm{H}_{3} \mathrm{BO}_{3}$; $1 \mathrm{gm}$ of $\mathrm{CaCl}_{2} \cdot 2 \mathrm{H}_{2} \mathrm{O} ; 1 \mathrm{gm}$ of KSCN for $5 \mathrm{~L}$ of deionized water. Each liter of artificial saliva prepared was diluted

Table 1: Products, manufacturers, and their components

\begin{tabular}{|c|c|c|c|}
\hline Group & Product & Manufacturer & Components \\
\hline CP-Water & Opalescence & $\begin{array}{l}\text { Ultradent Products Inc., } \\
\text { South Jordan, UT, EUA }\end{array}$ & $\begin{array}{l}\text { Carbamide peroxide } 10 \% \text {, potassium nitrate, sodium fluoride } \\
(1,100 \mathrm{ppm})\end{array}$ \\
\hline $\begin{array}{l}\text { CP-Listerine and } \\
\text { Listerine }\end{array}$ & $\begin{array}{l}\text { Listerine } \\
\text { Whitening }\end{array}$ & $\begin{array}{l}\text { KIK Custom Products, } \\
\text { Etobicoke, Canada }\end{array}$ & $\begin{array}{l}\text { Water, } 8 \% \text { alcohol, } 2 \% \text { hydrogen peroxide, sodium phosphate, } \\
\text { poloxamer } 407 \text {, sodium lauryl sulfate, sodium citrate, mint aroma, } \\
\text { menthol, eucalyptol, sodium saccharin, sucralose }\end{array}$ \\
\hline $\begin{array}{l}\text { CP-Colgate and } \\
\text { Colgate }\end{array}$ & $\begin{array}{l}\text { Colgate Total } \\
12 \text { Clean Mint }\end{array}$ & $\begin{array}{l}\text { Colgate-Palmolive, São } \\
\text { Bernardo do Campo, SP, } \\
\text { Brazil }\end{array}$ & $\begin{array}{l}\text { Water, hydrated silica, sodium lauryl sulfate, PVM/MA copolymer, } \\
\text { aroma, carrageenan, sodium hydroxide, triclosan, sodium } \\
\text { saccharin, } \mathrm{Cl} 77891 \text {, limonene, sodium fluoride }(1,450 \mathrm{ppm})\end{array}$ \\
\hline $\begin{array}{l}\text { CP-ColgateW and } \\
\text { ColgateW }\end{array}$ & $\begin{array}{l}\text { Colgate } \\
\text { Luminous } \\
\text { White }\end{array}$ & $\begin{array}{l}\text { Colgate-Palmolive, São } \\
\text { Bernardo do Campo, SP, } \\
\text { Brazil }\end{array}$ & $\begin{array}{l}1 \% \text { hydrogen peroxide, propylene glycol, calcium pyrophosphate, } \\
\text { glycerin, PEG/PPG-116/copolymer } 66 \text { PEG-12, silica, aroma, } \\
\text { tetrasodium pyrophosphate, sodium lauryl sulfate, disodium } \\
\text { pyrophosphate, sodium monofluorophosphate ( } 1,000 \mathrm{ppm})\end{array}$ \\
\hline $\begin{array}{l}\text { CP-OralBW and } \\
\text { OralBW }\end{array}$ & $\begin{array}{l}\text { Oral-B 3D } \\
\text { White Luxe }\end{array}$ & $\begin{array}{l}\text { Procter \& Gamble } \\
\text { Manufacturing GmbH, } \\
\text { Gross-Geraud, Germany }\end{array}$ & $\begin{array}{l}\text { Water, hydrated silica, sorbitol, disodium pyrophosphate, sodium } \\
\text { lauryl sulfate, sodium hydroxide, aroma, cellulose gum, sodium } \\
\text { saccharin, carbomer, xanthan gum, Cl } 77891 \text {, limonene, mica, } \\
\text { linalool, glycerin, Cl } 74160 \text {, sodium fluoride ( } 1,450 \mathrm{ppm})\end{array}$ \\
\hline $\begin{array}{l}\text { CP-CloseUpW } \\
\text { and CloseUpW }\end{array}$ & $\begin{array}{l}\text { CloseUp } \\
\text { Diamond } \\
\text { Attraction }\end{array}$ & $\begin{array}{l}\text { Unilever, Ipojuca, PE, } \\
\text { Brazil }\end{array}$ & $\begin{array}{l}\text { Blue covarine, water, hydrated silica, sorbitol, PEG-32, sodium lauryl } \\
\text { sulfate, aroma, mica, cellulose gum, sodium saccharin, trisodium } \\
\text { phosphate, PVM/MA copolymer, sodium fluoride (1,450 ppm) }\end{array}$ \\
\hline
\end{tabular}


in $1 \mathrm{~L}$ of deionized water and in a $\mathrm{NaHCO}_{3}$ (sodium bicarbonate) solution (0.4198 gm of $\mathrm{NaHCO}_{3}$ in 259.12 $\mathrm{mL}$ of deionized water) and adjusted to a $\mathrm{pH}$ of 7.0 with a $\mathrm{NaOH}$ solution. The artificial saliva was changed daily during the storage periods.

During the cycles, the specimens were stored in a bacteriological oven (ECB 11 Digital, Odontobrás, Ribeirão Preto, Brazil) at $37^{\circ} \mathrm{C}$. The whitening and dye-brush/rinse cycles were performed at room temperature $\left(25^{\circ} \mathrm{C}\right)$, and, during the staining and rinsing steps, the specimens were kept under constant agitation. The brushing procedure was performed manually by one operator with an electric toothbrush (Oral-B Cross Action Power Whitening, Procter \& Gamble Manufacturing GMBH, Gross-Geraud, Germany), on which a standardized amount of dentifrice was deposited on the enamel surface from a syringe.

\section{Color Assessment}

The color was assessed under standardized ambient conditions using a spectrophotometer (CM2600d, Konica Minolta, Osaka, Japan) and according to the Commission Internationale de l'Éclairage (CIE) L*a* b* system. Three color measurements were made of each specimen in each measurement period. The enamel surface was moist because the color measurement was taken immediately after immersion in artificial saliva and drying with an absorbent paper to remove excess artificial saliva. The device was adjusted to use the D65 standard light source with $100 \%$ ultraviolet light and the specular component included. The observer angle was set at $2^{\circ}$, and the device was adjusted to a small reading area. ${ }^{24,25}$ The color of each specimen was measured twice: After staining (M1) and after treatment (M2). The results of the color measurements were quantified with regard to the three coordinate values $\left(\mathrm{L}^{*}, \mathrm{a}^{*}\right.$, and $\left.\mathrm{b}^{*}\right)$ as established by the CIE, which locate the color of an object in a three-dimensional (3D) color space. The $L^{*}$ axis represents the degree of luminosity and ranges from 0 (black) to 100 (white). Axis a* represents the level of green/red color, and axis $b^{*}$ represents the level of blue/yellow color. The color was measured over a standard white background. Computations for the CIEDE2000 $\left(\Delta \mathrm{E}_{00}\right)$ color difference formula were made according to the following equation:

$$
\begin{gathered}
\Delta \mathrm{E}_{00}=\left[\left(\Delta \mathrm{L}^{\prime} / \mathrm{K}_{\mathrm{L}} \mathrm{S}_{\mathrm{L}}\right)^{2}+\left(\Delta \mathrm{C}^{\prime} / \mathrm{K}_{\mathrm{C}} \mathrm{S}_{\mathrm{C}}\right)^{2}+\left(\Delta \mathrm{H}^{\prime} / \mathrm{K}_{\mathrm{H}} \mathrm{S}_{\mathrm{H}}\right)^{2}+\mathrm{R}_{\mathrm{T}}\right. \\
\left.\left(\Delta \mathrm{C}^{\prime} / \mathrm{K}_{\mathrm{C}} \mathrm{S}_{\mathrm{C}}\right)\left(\Delta \mathrm{H}^{\prime} / \mathrm{K}_{\mathrm{H}} \mathrm{S}_{\mathrm{H}}\right)\right]^{1 / 2}
\end{gathered}
$$

where $\Delta \mathrm{L}^{\prime}, \Delta \mathrm{C}^{\prime}$, and $\Delta \mathrm{H}^{\prime}$ are the differences in lightness, chroma, and hue for before and after aging in CIEDE2000 and where $R_{T}$ is a function (rotation function) that accounts for the interaction between chroma and hue differences in the blue region. Weighting functions, $S_{L}$, $\mathrm{S}_{\mathrm{C}}$, and $\mathrm{S}_{\mathrm{H}}$, adjust the total color difference for variation in the location of the color difference in the $\mathrm{L}^{\prime}, \mathrm{a}^{\prime}$, and $\mathrm{b}^{\prime}$ coordinates and the parametric factors $\mathrm{K}_{\mathrm{L}}, \mathrm{K}_{\mathrm{C}}$, and $\mathrm{K}_{\mathrm{H}}$ are correction terms for experimental conditions.

\section{Microhardness Measurement}

The surface microhardness of all specimens was obtained using a microhardness tester (FM-700, Future-Tech, Tokyo, Japan) with a Knoop indenter under a $0.25 \mathrm{~N}$ load for 10 seconds at baseline and after whitening. Three indentations were made in each specimen, $100 \mu \mathrm{m}$ apart, and their average was calculated to represent the specimen microhardness value (Knoop hardness number, $\mathrm{KHN}$ ). All measurements were performed by the same examiner using the same calibrated machine.

\section{Statistical Analysis}

Statistical analysis was performed using the Statistica for Windows software (StatSoft, Tulsa, USA). The values of color and microhardness were submitted to the Kolmogorov-Smirnov normality test. Data were statistically analyzed using one-way ANOVA and the Tukey test for color measurement. For microhardness analysis, paired $t$-tests were conducted to compare values at baseline (M1) and after whitening (M2), group by group. The significance level adopted was 5\%.

\section{RESULTS}

\section{Color}

Data of color change (means and standard deviation) are presented in Table 2. Negative changes were observed for $\Delta b^{*}$ values, except for Water and $B$. The $b^{*}$ values decreased during the experiment, reflecting a reduced yellowness in the specimens. Therefore, one-way ANOVA for $\Delta \mathrm{E}_{00}$ was performed only for groups that showed a whitening effect (negative values of $\Delta \mathrm{b}^{*}$ and positive values of $\Delta \mathrm{L}^{*}$ ). The ANOVA showed a significant difference among the groups and the Tukey test showed that color change was statistically higher in all groups whitened with $10 \% \mathrm{CP}$ associated with OTC products (Table 2). The teeth subjected to toothpaste with blue covarine $(\mathrm{CloseUpW})$ also presented results similar to those of $10 \% \mathrm{CP}$.

Graph 1 presents the reflectance curves of the mean values at baseline and after treatment for all subgroups.

\section{Microhardness}

The overall microhardness at baseline (M1) and after whitening (M2) is shown in Table 3. Colgate produced a significant increase in microhardness after the whitening treatment. 
Effect of Over-the-counter Whitening Products

Table 2: Mean and SD of $\Delta \mathrm{L}^{*}, \Delta \mathrm{a}^{*}, \Delta \mathrm{b}^{*}$, and $\Delta \mathrm{E} 00$ for all groups

\begin{tabular}{|c|c|c|c|c|}
\hline & $\Delta L^{*}$ & $\Delta a^{*}$ & $\Delta b^{*}$ & $\triangle E 00$ \\
\hline Treatment & Mean $\pm S D$ & Mean $\pm S D$ & Mean $\pm S D$ & Mean $\pm S D$ \\
\hline CP-Water & $4.48 \pm 3.33$ & $-0.14 \pm 0.90$ & $-5.77 \pm 2.12$ & $6.88 a b^{*} \pm 2.80$ \\
\hline CP-Brushing & $3.10 \pm 2.18$ & $0.18 \pm 0.90$ & $-5.30 \pm 2.10$ & $5.85 a b \pm 2.19$ \\
\hline CP-Listerine & $4.30 \pm 1.96$ & $0.25 \pm 0.90$ & $-4.93 \pm 1.20$ & $6.11 \mathrm{ab} \pm 1.49$ \\
\hline CP-Colgate & $3.11 \pm 1.86$ & $0.25 \pm 0.48$ & $-4.52 \pm 1.55$ & $5.35 a b \pm 1.02$ \\
\hline CP-ColgateW & $4.13 \pm 2.68$ & $0.14 \pm 0.70$ & $-4.51 \pm 2.16$ & $5.71 \mathrm{ab} \pm 2.72$ \\
\hline CP-OralBW & $3.68 \pm 2.08$ & $0.39 \pm 0.40$ & $-4.31 \pm 1.81$ & $5.34 a b \pm 2.02$ \\
\hline CP-CloseUpW & $2.58 \pm 2.18$ & $-0.44 \pm 0.38$ & $-5.53 \pm 2.16$ & $5.86 a b \pm 1.86$ \\
\hline Water & $-6.15 \pm 4.35$ & $-0.14 \pm 1.83$ & $3.76 \pm 3.03$ & $7.56 \pm 3.73$ \\
\hline Brushing & $-3.02 \pm 2.46$ & $-0.57 \pm 0.41$ & $0.73 \pm 2.21$ & $4.02 \pm 1.29$ \\
\hline Listerine & $1.01 \pm 1.52$ & $-0.70 \pm 0.38$ & $-2.71 \pm 1.35$ & $3.20 c \pm 1.18$ \\
\hline Colgate & $1.86 \pm 1.38$ & $-0.69 \pm 0.31$ & $-0.70 \pm 1.16$ & $2.49 c \pm 0.88$ \\
\hline ColgateW & $0.35 \pm 1.55$ & $-0.59 \pm 0.64$ & $-2.41 \pm 1.48$ & $3.00 c \pm 1.16$ \\
\hline OralBW & $0.96 \pm 2.54$ & $-0.73 \pm 0.60$ & $-1.83 \pm 1.77$ & $3.13 c \pm 1.65$ \\
\hline CloseUpW & $3.08 \pm 1.66$ & $-1.50 \pm 0.92$ & $-1.94 \pm 1.81$ & $4.40 \mathrm{bc} \pm 1.48$ \\
\hline
\end{tabular}

${ }^{*}$ Different letters mean significant differences among treatments $(p<0.05)$. SD: Standard deviation

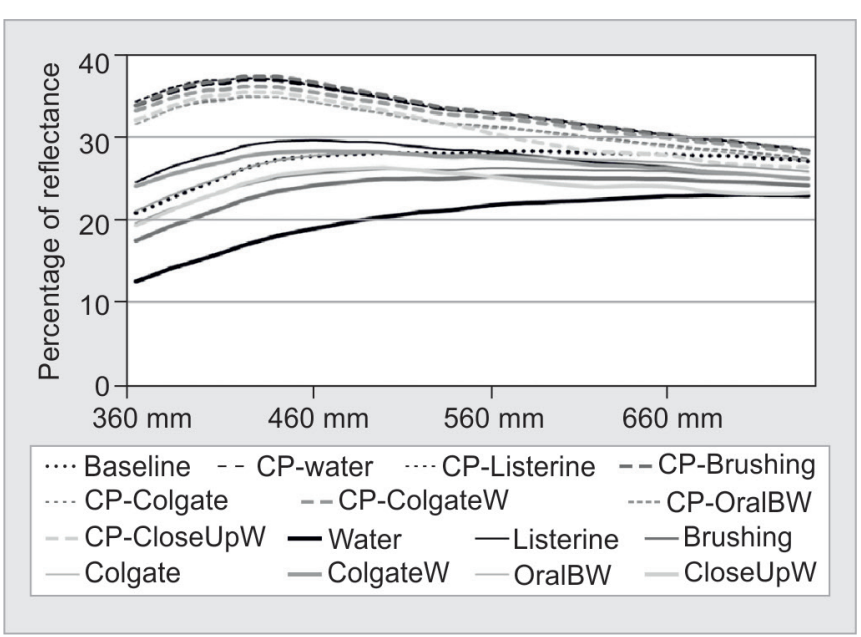

Graph 1: Reflectance curves of all subgroups at baseline and after whitening treatment

Table 3: Mean and standard deviation of microhardness (KHN) at M1, M2

\begin{tabular}{lll}
\hline Group & Baseline (M1) & After whitening (M2) \\
\hline CP-Water & $277.69(55.40)$ & $262.37(60.67)$ \\
CP-Brushing & $286.39(42.48)$ & $262.45(47.03)$ \\
CP-Listerine & $266.07(46.34)$ & $275.69(45.97)$ \\
CP-Colgate & $269.93(52.13)$ & $268.53(68.91)$ \\
CP-ColgateW & $292.49(37.68)$ & $287.24(32.60)$ \\
CP-OralBW & $286.33(41.77)$ & $268.26(56.83)$ \\
CP-CloseUpW & $277.98(47.64)$ & $276.89(59.17)$ \\
Water & $281.91(41.99)$ & $285.67(22.06)$ \\
Brushing & $261.41(46.78)$ & $276.29(36.84)$ \\
Listerine & $286.35(43.03)$ & $292.47(21.71)$ \\
Colgate & $259.25(35.35)^{\star}$ & $291.86(20.25)^{\star}$ \\
ColgateW & $267.97(52.46)$ & $289.86(19.19)$ \\
OralBW & $260.67(80.30)$ & $291.79(23.26)$ \\
CloseUpW & $289.28(51.90)$ & $281.10(20.78)$ \\
\hline *Significant
\end{tabular}

*Significant difference between M1 and M2 for each group using a paired t-test $(p<0.05)$

\section{DISCUSSION}

This study evaluated the effect of OTC whitening agents on tooth color and microhardness and the addition of 10\% $\mathrm{CP}$ to at-home whitening treatment. The results showed that the OTC whitening agents produced statistically different color change. Water presented the highest value for $\Delta \mathrm{E}$, and the $\Delta \mathrm{b}^{*}$ value was positive, which means that there was a yellowing of specimens. The analysis of the $\Delta \mathrm{b}^{*}$ of the water and brushing groups showed a yellowing effect because this value was positive. For this reason, ANOVA and the Tukey test were applied only to the groups that presented the whitening effect (negative $\left.\Delta b^{*}\right)$. The staining in the brushing and water group was confirmed by reflectance curves, which decreased after 12 weeks of treatment as compared with the baseline condition.

The presence of $1 \%$ hydrogen peroxide in whitening dentifrices has no consistent whitening effect by itself. Whitening was increased by including abrasive particles, such as hydrated silica in the composition. According to previous studies, ${ }^{26,27}$ the removal of extrinsic stains with this toothpaste is improved compared with conventional toothpaste, which contains only hydrated silica particles. However, in this study, the tested toothpaste with $1 \%$ hydrogen peroxide (ColgateW) presented a whitening effect similar to that of conventional toothpaste because it contained abrasive particles in the composition. During toothbrushing, the abrasive particles are trapped between the tips of the toothbrush bristles and the stained tooth surface. Since the abrasive particles are physically harder than the superficial staining, this is removed leaving a clean tooth surface. ${ }^{28}$ Thus, the abrasive cleaning mechanism mainly influences the extrinsic stains and does not significantly affect any underlying intrinsic staining or 
the natural color of the tooth. This finding is consistent with previous studies that concluded that conventional dentifrices could outperform or have a similar whitening effect to whitening toothpaste. ${ }^{13,29-31}$

The OralBW group was whitened by the toothpaste. Abrasive dentifrices usually contain hydrated silica, an abrasive agent that has silica particles in different sizes and shapes and that can influence the whitening effect on teeth. ${ }^{32}$ Hydrated silica can be found in conventional dentifrices, but whitening dentifrices contain more abrasives particles or a combination of abrasive agents, and their abrasiveness eliminates the pellicle, extrinsic pigments, and adherent stains. ${ }^{33}$

The whitening effect observed in the Colgate group can be attributed to the presence of hydrated silica and the mechanical action of toothbrush bristles associated with the presence of triclosan and polyvinyl methyl ether $(\mathrm{PVM}) /$ maleic acid (MA) in conventional dentifrice formulations. These substances are anticalculus agents that prevent calculus formation and can help guard against bacteria pigments. In a previous study, ${ }^{34}$ good removal of extrinsic stains incorporated in calculus and biofilm was reported.

The CloseUpW group demonstrated effective whitening, with results statistically similar to those of all groups that had 10\% CP (Table 2). In addition to the presence of hydrated silica in its composition that can remove extrinsic stains, this dentifrice contains blue covarine. Blue covarine is a blue-colored agent, whose whitening effect is based on depositing a thin blue film on the enamel's surface, thus modifying the perception of the tooth color. ${ }^{35}$ Studies have reported an yellow-toblue tooth color shift (reduction in $\mathrm{b}^{*}$ ) in teeth treated with toothpaste containing blue covarine, ${ }^{36-38}$ and the same phenomenon was found in the present study. The deposition of blue covarine is relatively uniform across the enamel surface and has good retention on the tooth, thus giving the enamel an optical whitening effect. ${ }^{39}$ However, the longevity of the whitening effect provided by blue covarine was not analyzed. This effect is instantaneous and temporary ${ }^{40-42}$ because the thin film formed can be removed by saliva and food. Although CloseUp Diamond Attraction has a similar effect to $10 \%$ CP immediately after brushing, it would not have the same longevity as at-home bleaching.

Groups that used only the whitening agents Listerine, Colgate Total 12, Colgate Luminous White, and Oral-B 3D White Luxe showed a significant difference in color change $(\Delta \mathrm{E})$ and a consistent difference in reflectance curves when compared with $10 \% \mathrm{CP}$ at-home bleaching with or without OTC bleaching products. Despite the presence of hydrogen peroxide or abrasives in toothpaste and mouth rinse composition, the whitening effect of some OTC bleaching agents was not similar to or higher than that of at-home bleaching with $10 \% \mathrm{CP}$. This fact agrees with what had already been concluded in previous studies. ${ }^{12-14,31}$ Furthermore, the association of OTC with $10 \% \mathrm{CP}$ did not enhance the whitening effect of at-home whitening, since no difference was observed among $\mathrm{CP}$ groups with OTC and $\mathrm{CP}$-Water that was used as a control.

Reflectance curves represent the light reflected by an object at different wavelengths. These curves are obtained by values collected after color measurement in a reflectance spectrophotometer. The higher the reflectance percentage, the more the object reflects, and it has a lighter appearance. In general, compared with baseline, an increase in the percentage of reflectance was observed in the subgroups that had specimens whitened by $10 \% \mathrm{CP}$ associated with OTC products (Graph 1 ). In the brushing and water groups, the reflectance decreased after 12 weeks of treatment, compared with the baseline condition. The major changes were observed near 410 to $460 \mathrm{~nm}$, which is the spectral region corresponding to blue reflection.

The percentage loss of surface microhardness was calculated. Microhardness remained similar in almost all subgroups after whitening treatment with cycles of rinsing/brushing and whitening gel application. The microhardness of the Colgate group increased significantly and was different from the baseline. Although all subgroups were in constant contact with saliva during the storage periods and underwent the same remineralizing action of sodium fluoride in all toothpaste composition, ${ }^{16,43}$ the OTC whitening agent mechanism with hydrogen peroxide, blue covarine, or abrasive silica can decrease the mineral content of the enamel, although remineralization is induced by sodium fluoride and artificial saliva.

Additional clinical research is indicated to provide more information about the performance of these products, especially new products which have different tooth whitening mechanisms.

\section{CONCLUSION}

Based on the methodologies and according to the statistical analysis, it was concluded that the association of 10\% $\mathrm{CP}$ at-home bleaching treatment with OTC whitening agents did not increase the whitening effect and did not influence the surface microhardness. The OTC whitening agents that contain hydrogen peroxide and abrasives in their compositions had similar effects. However, they were not as effective as subgroups bleached with 10\% CP. The blue covarine optical technology toothpaste had 
a similar effect to $10 \% \mathrm{CP}$ at-home bleaching immediately after brushing.

\section{REFERENCES}

1. Johnston WM, Kao EC. Assessment of appearance match by visual observation and clinical colorimetry. J Dent Res 1989 May;68(5):819-822.

2. Xiao J, Zhou XD, Zhu WC, Zhang B, Li JY, Xu X. The prevalence of tooth discolouration and the self-satisfaction with tooth colour in a Chinese urban population. J Oral Rehabil 2007 May;34(5):351-360.

3. Joiner A, Jones N, Raven S. Investigation of factors influencing stain formation utilizing an in situ model. Adv Dent Res 1995 Dec;9(4):471-476.

4. Dahl JE, Pallesen U. Tooth bleaching - a critical review of the biological aspects. Crit Rev Oral Biol Med 2003;14(4):292-304.

5. Joiner A. Tooth colour: a review of the literature. J Dent 2004;32 (Suppl 1):3-12.

6. Sulieman M, Addy M, Macdonald E, Rees JS. The bleaching depth of a $35 \%$ hydrogen peroxide based in-office product: a study in vitro. J Dent 2005 Jan;33(1):33-40.

7. Joiner A. Review of the extrinsic stain removal and enamel/ dentine abrasion by a calcium carbonate and perlite containing whitening toothpaste. Int Dent J 2006 Aug;56(4): 175-180.

8. Torres CR, Wiegand A, Sener B, Attin T. Influence of chemical activation of a $35 \%$ hydrogen peroxide bleaching gel on its penetration and efficacy-in vitro study. J Dent 2010 Oct;38(10):838-846.

9. Torres CR, Crastechini E, Feitosa FA, Pucci CR, Borges AB. Influence of $\mathrm{pH}$ on the effectiveness of hydrogen peroxide whitening. Oper Dent 2014 Nov-Dec;39(6):E261-E268.

10. Leonard RH, Sharma A, Haywood VB. Use of different concentrations of carbamide peroxide for bleaching teeth: an in vitro study. Quintessence Int 1998 Aug;29(8):503-507.

11. Bernardon JK, Sartori N, Ballarin A, Perdigão J, Lopes GC, Baratieri LN. Clinical performance of vital bleaching techniques. Oper Dent 2010 Jan-Feb;35(1):3-10.

12. Jaime IM, França FM, Basting RT, Turssi CP, Amaral FL. Efficacy of hydrogen-peroxide-based mouthwash in altering enamel color. Am J Dent 2014 Feb;27(4):47-50.

13. Dantas AA, Bortolatto JF, Roncolato Á, Merchan H, Floros MC, Kuga MC, de Oliveira Junior OB. Can a bleaching toothpaste containing blue covarine demonstrate the same bleaching as conventional techniques? An in vitro, randomized and blinded study. J Appl Oral Sci 2015 Nov-Dec;23(6):609-613.

14. Karadas M, Hatipoglu O. Efficacy of mouthwashes containing hydrogen peroxide on tooth whitening. Sci World J 2015;2015:961403.

15. Torres CR, Perote LC, Gutierrez NC, Pucci CR, Borges AB. Efficacy of mouth rinses and toothpaste on tooth whitening. Oper Dent 2013 Jan-Feb;38(1):57-62.

16. Salomão D, Santos D, Nogueira R, Palma-Dibb R, GeraldoMartins V. Acid demineralization susceptibility of dental enamel submitted to different bleaching techniques and fluoridation regimens. Oper Dent 2014 Jul-Aug;39(4):E178-E185.

17. Kaur S, Makkar S, Kumar R, Pasricha S, Gupta P. Comparative evaluation of surface properties of enamel and different esthetic restorative materials under erosive and abrasive challenges: an in vitro study. Indian J Dent 2015 Oct-Dec; 6(4):172-180.
18. Ghanbarzadeh M, Ahrari F, Akbari M, Hamzei H. Microhardness of demineralized enamel following home bleaching and laser-assisted in office bleaching. J Clin Exp Dent 2015 Jul;7(3):e405-e409.

19. Moosavi H, Darvishzadeh F. The influence of post bleaching treatments in stain absorption and microhardness. Open Dent J 2016 Mar;10:69-78.

20. Attin T, Schmidlin PR, Wegehaupt F, Wiegand A. Influence of study design on the impact of bleaching agents on dental enamel microhardness: a review. Dent Mater 2009 Feb;25(2): 143-157.

21. Wozniak WT, Naleway CA, Gonzalez E, Schemehorn BR, Stookey GK. Use of an in vitro model to assess the effects of APF gel treatment on the staining potential of dental porcelain. Dent Mater 1991 Oct;7(4):263-267.

22. Association AD. ADA Professional Product Review. In-Office Whitening Agents: Laboratory Testing Methods; 2008.

23. Göhring TN, Zehnder M, Sener B, Schmidlin PR. In vitro microleakage of adhesive-sealed dentin with lactic acid and saliva exposure: a radio-isotope analysis. J Dent 2004 Mar;32(3):235-240.

24. ISO. Dentistry: Guidance on Colour Measurement; 2011;TR 28642:1-10.

25. Ghassemi A, Hooper W, Vorwerk L, Domke T, DeSciscio P, Nathoo S. Effectiveness of a new dentifrice with baking soda and peroxide in removing extrinsic stain and whitening teeth. J Clin Dent 2012;23(3):86-91.

26. Horn BA, Bittencourt BF, Gomes OM, Farhat PA. Clinical evaluation of the whitening effect of over-the-counter dentifrices on vital teeth. Braz Dent J 2014;25(3):203-206.

27. Joiner A. Whitening toothpastes: a review of the literature. J Dent 2010;38 (Suppl 2).e17-2.e24.

28. Lewis R, Dwyer-Joyce RS, Pickles MJ. Interaction between toothbrushes and toothpaste abrasive particles in simulated tooth cleaning. Wear 2004 Aug;257(3-4):368-376.

29. Demarco FF, Meireles SS, Masotti AS. Over-the-counter whitening agents: a concise review. Braz Oral Res 2009;23 (Suppl1): 64-70.

30. Alshara S, Lippert F, Eckert GJ, Hara AT. Effectiveness and mode of action of whitening dentifrices on enamel extrinsic stains. Clin Oral Investig 2014;18(2):563-569.

31. Soares CN, Amaral FL, Mesquita MF, Franca FM, Basting RT, Turssi CP. Toothpastes containing abrasive and chemical whitening agents: efficacy in reducing extrinsic dental staining. Gen Dent 2015 Nov-Dec;63(6):e24-e28.

32. Pinto SC, Hilgenberg SP, Wambier DS, Farago PV, Bandéca MC, Santos FA. Characterization of dentifrices containing desensitizing agents, triclosan or whitening agents: EDX and SEM analysis. Braz Dent J 2014;25(2):153-159.

33. AttiaML,Cavalli V, doEspíritoSantoAM,MartinAA, D'ArceMB, Aguiar FH, Lovadino JR, do Rego MA, Cavalcanti AN, Liporoni PC. Effects of bleaching agents combined with regular and whitening toothpastes on surface roughness and mineral content of enamel. Photomed Laser Surg 2015 Jul;33(7):378-383.

34. van Loveren C, Duckworth RM. Anti-calculus and whitening toothpastes. Monogr Oral Sci 2013;23:61-74.

35. Bortolatto JF, Dantas AA, Roncolato Á, Merchan H, Floros MC, Kuga MC, Oliveira Junior OB. Does a toothpaste containing blue covarine have any effect on bleached teeth? An in vitro, randomized and blinded study. Braz Oral Res 2016;30:pii: S1806-83242016000100226. 
36. Collins LZ, Naeeni M, Platten SM. Instant tooth whitening from a silica toothpaste containing blue covarine. J Dent 2008;36 (Suppl 1):S21-S25.

37. Joiner A. A silica toothpaste containing blue covarine: a new technological breakthrough in whitening. Int Dent J 2009 Oct;59(5):284-288.

38. Pintado-Palomino K, Vasconcelos CV, Silva RJ, Fressatti AL, Motta BJ, Pires-DE-Souza FC, Tirapelli C. Effect of whitening dentifrices: a double-blind randomized controlled trial. Braz Oral Res 2016 Oct 10;30(1):e82.

39. Joiner A, Philpotts CJ, Ashcroft AT, Laucello M, Salvaderi A. In vitro cleaning, abrasion and fluoride efficacy of a new silica based whitening toothpaste containing blue covarine. J Dent 2008;36 (Suppl 1):S32-S37.
40. Tao D, Smith RN, Zhang Q, Sun JN, Philpotts CJ, Ricketts SR, Naeeni M, Joiner A. Tooth whitening evaluation of blue covarine containing toothpastes. J Dent 2017 Dec;67S: S20-S24.

41. Tao D, Sun JN, Wang X, Zhang Q, Naeeni MA, Philpotts CJ, Joiner A. In vitro and clinical evaluation of optical tooth whitening toothpastes. J Dent 2017 Dec;67S:S25-S28.

42. Westland S, Luo W, Li Y, Pan Q, Joiner A. Investigation of the perceptual thresholds of tooth whiteness. J Dent 2017; 67S:S11-S14.

43. Ionta FQ, Mendonça FL, de Oliveira GC, de Alencar CR, Honório HM, Magalhães AC, Rios D. In vitro assessment of artificial saliva formulations on initial enamel erosion remineralization. J Dent 2014 Feb;42(2):175-179. 